Rev. Elet. em Gestão, Educação e Tecnologia Ambiental (e-ISSN: 2236-1170)

\title{
USO DE TÉCNICAS COMBINADAS PARA O TRATAMENTO DE EFLUENTES TÊXTEIS: SEPARAÇÃO FÍSICO-QUIMICA E FOTODEGRADAÇÃO UV- $\mathrm{H}_{2} \mathrm{O}_{2}$
}

\author{
Carlos Enrique Jerônimo \\ Petroleo Brasileiro AS, c enrique@hotmail.com
}

http://dx.doi.org/10.5902/223611706244

\section{RESUMO}

O presente trabalho teve como objetivo, avaliar a técnica combinada (físico-química e oxidativa), que se baseia na aplicação de coagulantes, seguida do uso da radiação UV em conjunto com o peróxido de hidrogênio $\left(\mathrm{H}_{2} \mathrm{O}_{2}\right)$, a fim de se degradar a matéria orgânica presente em um efluente industrial têxtil. Os experimentos foram divididos em duas etapas, na primeira etapa buscou-se uma referência para o processo de coagulação, em termos de variáveis operacionais, que direcionem para a caracterização do $\mathrm{pH}$ dito como "ideal", bem como, para a partir de então, se efetuar a varredura para se determinar a dosagem de reagente coagulante, necessária para se obter níveis satisfatórios de eficiência (remoção de turbidez superior a $80 \%$ ). A realização dos testes de jarro foi realizada com ajustes de $\mathrm{pH}(3,0$ a 12,0 com variação de 2,0) e a inserção do agente coagulante $(10$ a $300 \mathrm{mg} / \mathrm{L}$ ). Os resultados apontam para as condições ideais em $\mathrm{pH}$ igual a 3,0 , com a adição de $100 \mathrm{mg} / \mathrm{L}$ do agente coagulante, sulfato de alumínio $\mathrm{Al}_{2} \mathrm{SO}_{4}$. Todos os experimentos foram realizados a uma temperatura ambiente. A segunda etapa do processo foi o tratamento do sobrenadante, resultante da primeira etapa, utilizando-se o processo oxidativo, realizado em um reator fotoquímico com o devido controle de temperatura, emissão da radiação (via uma lâmpada de vapor de mercúrio de meia pressão isenta do bulbo). Durante os experimentos foi mantida constante a temperatura a 37,5 으 (derivada do aquecimento gerado pela lâmpada), através da passagem da água de arrefecimento do sistema. Utilizou-se uma relação de $1 \mathrm{~L}$ de efluente para $0,1 \mathrm{~L}$ de peróxido de hidrogênio $(102 \mathrm{~g} / \mathrm{L})$, em seguida as misturas foram submetidas à agitação, seguida da exposição contínua a radiação UV por 120 minutos. As reações foram monitoradas por meio da Demanda Química de Oxigênio (DQO) e a turbidez. Os resultados encontrados para a remoção da Demanda Química de Oxigênio (DQO) foram da ordem de 80\% e redução da turbidez para valores da ordem de 1,8 NTU.

PALAVRAS-CHAVE: Efluentes Têxteis, Coagulação, Floculação e Fotoquímica.

\section{COMBINED USE OF TECHNICAL TEXTILES FOR WASTEWATER TREATMENT: PHYSICAL AND CHEMICAL SEPARATION AND PHOTODEGRADATION UV- $\mathrm{H}_{2} \mathrm{O}_{2}$}

\begin{abstract}
This study aimed to assess the combined technique (chemical and physico-oxidation), which is based on application of coagulant, followed by the use of UV in combination with hydrogen peroxide ( $\mathrm{H} 2 \mathrm{O} 2$ ), in order to degrade the organic matter present in a textile effluent. The experiments were divided into two stages, the first step was sought to a reference to the coagulation process, in terms of operational variables to direct characterization of the $\mathrm{pH}$ to said to be "ideal" and to thereafter, effecting a scan to determine the dosage of coagulant reagent,
\end{abstract}


Rev. Elet. em Gestão, Educação e Tecnologia Ambiental (e-ISSN: 2236-1170)

necessary to obtain satisfactory levels of efficiency (removal of turbidity greater than $80 \%$ ). The testing of jar was carried out with $\mathrm{pH}$ adjustment (3.0 to 12.0 with change 2.0 ) and the insertion of

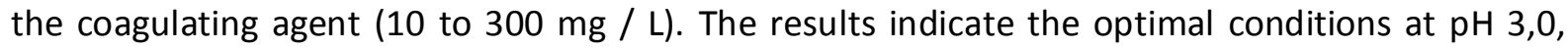
with the addition of $100 \mathrm{mg} / \mathrm{L}$ of the coagulant, aluminum sulfate Al2SO4. All experiments were done at room temperature. The second process step is the treatment of the supernatant resulting from the first step, using the oxidation process, performed in a photochemical reactor with proper temperature control, emission of radiation (via a mercury vapor lamp middle pressure free bulb). During the experiments the temperature was kept constant at $37.5^{\circ} \mathrm{C}$ (derived from the heat generated by the lamp), by passing the cooling water system. We used a relation of $1 \mathrm{~L}$ to $0.1 \mathrm{~L}$ effluent of hydrogen peroxide $(102 \mathrm{~g} / \mathrm{L})$, then the mixtures were subjected to agitation, followed by continuous exposure to UV for 120 minutes. The reactions were monitored by chemical oxygen demand (COD) and turbidity. The results for the removal of Chemical Oxygen Demand (COD) were approximately $80 \%$ and reduced turbidity to values of about 1.8 NTU.

KEYWORDS: Effluents, Coagulation, Flocculation and Photochemistry.

\section{INTRODUÇÃO}

Os efeitos tóxicos da descarga de efluentes industriais em mananciais hídricos devem ser intensamente investigados, uma vez que podem afetar a sobrevivência, o comportamento ou a composição genética dos organismos aquáticos, bem como a saúde da população, que busca nestes mananciais seu suprimento de água potável (LEMOS et al. (1992)).

A indústria têxtil gera efluentes com composição extremamente heterogênea e uma grande quantidade de material tóxico e recalcitrante, o que torna seu tratamento mais difícil. Esses efluentes apresentam uma forte coloração, uma grande quantidade de sólidos suspensos, $\mathrm{pH}$ altamente flutuante, temperatura elevada, grandes concentrações de DQO, considerável quantidade de metais pesados (ex. $\mathrm{Cr}, \mathrm{Ni}$ ou $\mathrm{Cu}$ ), compostos orgânicos clorados e surfactantes. (CISNEROS; ESPINOZA; LITTER; 2002)

Os processos físico-químicos, como coagulação/floculação, adsorção com carvão ativado e membranas têm sido desenvolvidos para remover a cor em efluentes têxteis, entretanto, essas tecnologias somente transferem o corante de fase, não resolvendo essencialmente o problema. (POON; HUANG; FUNG; 1999).

No caso dos Processos de Oxidação Avançados (POA's), esses são tecnologias que geralmente utilizam um forte agente oxidante (O3, $\mathrm{H} 2 \mathrm{O} 2)$ e/ou catalisadores ( $\mathrm{Fe}, \mathrm{Mn}, \mathrm{TiO} 2)$ na presença ou não de fonte de irradiação, para gerar radicais livres $\bullet O H\left(E^{0}=2,80 \mathrm{~V}\right)$, altamente reativos, capazes de mineralizar substâncias orgânicas refratárias, presentes nos efluentes industriais (SWAMINATHAN, $\mathrm{K}$ et al 2003,). Um método direto para geração de $\bullet \mathrm{OH}$ é a fotoclivagem do peróxido de hidrogênio por meio de irradiação UV. O processo $\mathrm{H}_{2} \mathrm{O}_{2} / U V$ pode levar à degradação completa e à conversão a $\mathrm{CO}_{2}$ e $\mathrm{H}_{2} \mathrm{O}$ e sais inorgânicos da maioria dos contaminantes orgânicos. (ARAUJO; YOKOYAMA; 2006).

Segundo Kempka et al (2012) nas últimas décadas, métodos de tratamento químico envolvendo a geração de radicais hidroxila, conhecido como Processos Oxidativos Avançados (POA) têm sido aplicados com êxito para a remoção ou degradação de poluentes que possam 
Rev. Elet. em Gestão, Educação e Tecnologia Ambiental (e-ISSN: 2236-1170)

causar eutrofização com base no alto poder oxidativo do radical hidroxila (HO•).

A eficiência da oxidação pelos reagentes de Fenton depende de vários fatores como: $\mathrm{pH}$, temperatura, e as concentrações de $\mathrm{H}_{2} \mathrm{O}_{2}$ e $\mathrm{Fe}^{2+}$. Na maioria dos estudos publicados, o efeito de cada variável foi estudada independente, com as demais variáveis mantidas constantes. Esta abordagem é um método demorado e muitas vezes ineficiente, pois as interações entre as variáveis e os efeitos dessas interações no processo não são determinados. Sendo assim, a aplicação do processo de oxidação vem sendo direcionador de inúmeros estudos, entre os quais Georgiou (2002), Lacerda (2004), Brião (2007), Bautista (2007), Agladze (2007) e Kempka et al (2012). Tendo-se destaque para uso das técnicas fotoquímicas, com um tratamento prévio, para obtenção de efluentes de alta qualidade e performance de tratamento.

Sendo assim, neste trabalho, realizou-se um estudo com ensaios experimentais realizados a partir de um efluente oriundo do processo de alvejamento de tecidos, utilizando o peróxido de hidrogênio como agente alvejante. $O$ efluente possui uma alta concentração de matéria orgânica (benzidinas, azo aromáticos e aminas), e devido a presença de agentes oxidantes residuais tornase uma alternativa em potencial para a aplicação da técnica do $\mathrm{UV}-\mathrm{H}_{2} \mathrm{O}_{2}$. Entretanto, como meio de reduzir a carga adicional de oxidante para o tratamento, se investigou a possibilidade da combinação de técnicas físico-químicas, como pré-tratamento (coagulação / floculação), utilizando-se o sulfato de alumínio.

\section{METODOLOGIA}

Os efluentes foram coletados em uma indústria têxtil - localizada em Natal, Capital do estado do Rio Grande do Norte, após a liberação para o sistema de tratamento primário da unidade, de formas homogêneas, oriundas do processo de alvejamento de tecidos, utilizando o peróxido de hidrogênio. Os efluentes foram coletados em três diferentes níveis de emprego no processo, ou seja, concentrações: para a lavagem numa relação de 1:10, em uma relação de lavagem na proporção de 1:5 e amostra de toda a mistura de efluentes gerados no processo, considerado como amostra bruta.

O conhecimento composicional dos efluentes foi investigado, de forma a aproveitar as potencialidades de tratamento, no tocante a fotodegradação ou degradação biológica, bem como, feita uma correlação para os níveis de aplicação das técnicas de caracterização, obtendo-se com isso a confirmação de que a técnica da Demanda Química de Oxigênio atende as expectativas de monitoramento e qualidade do efluente.

Durante as duas etapas de experimentos foram utilizados os seguintes reagentes para análise: peróxido de hidrogênio $30 \%$ em peso $(\mathrm{m} / \mathrm{m})$, ácido sulfúrico, sulfato de alumínio, molibdato de amônio, iodeto de potássio e tiossulfato de sódio.

Para os ensaios de coagulação/floculação, foi utilizado um equipamento de Jar-Test, dotado de um sistema de controle de agitação composto de seis jarros com capacidade de $1 \mathrm{~L}$, vide Figura 1. 0 ensaio foi realizado a temperatura ambiente. 


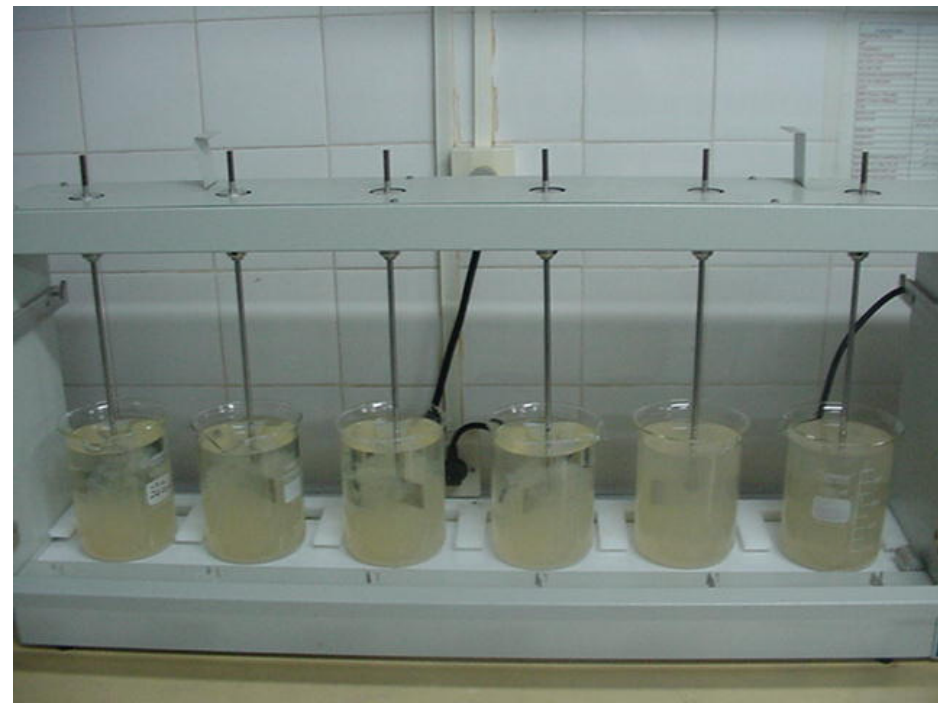

Figura 1. Esquema do teste de coagulação/floculação (Jar-Test).

Os experimentos utilizando o processo de oxidação avançada $\mathrm{UV} / \mathrm{H}_{2} \mathrm{O}_{2}$, foram realizados em um reator fotoquímico com luz artificial e capacidade de $4 \mathrm{~L}$, com uma lâmpada de vapor de mercúrio (400W) de média pressão, concêntrica, vide Figura 2. O reator foi mantido à temperatura constante, através de mangueiras de silicone, com fluxo contínuo de água de arrefecimento responsável pela manutenção da temperatura de todo processo em 37,5 oC. $O$ reator foi isolado por uma caixa de madeira vedada, para proteger os operadores contra a radiação emitida pela lâmpada.
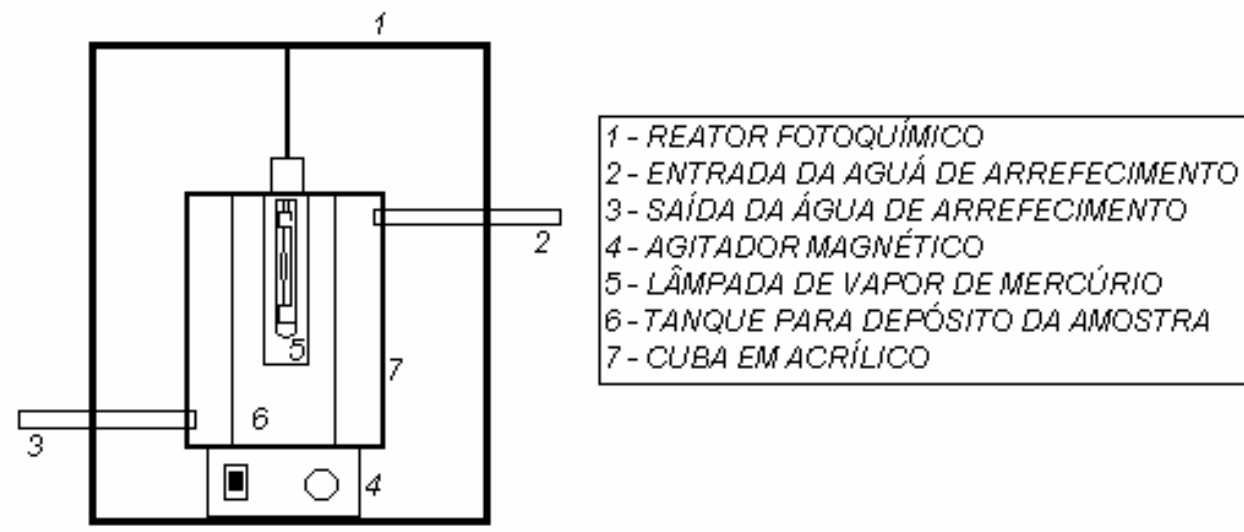

Figura 2. Esquema do reator fotoquímico.

Os ensaios para etapa de coagulação/floculação foram realizados com um volume total de $1 \mathrm{~L}$ de solução no sistema. O procedimento experimental foi realizado seguindo das etapas de: distribuição das amostras dos efluentes nos seis jarros; ligava-se o agitador; calibrava-se o agitador a uma rotação de $30 \mathrm{rpm}$; adicionava-se o ácido sulfúrico $98 \%$ ou solução de soda cáustica para ajuste do $\mathrm{pH}(3,0$ a 12,0$)$ das amostras (mediante dosagem padronizada por uma curva de acidificação e aferida por um pHmetro); adicionava-se o agente coagulante sulfato de 
Rev. Elet. em Gestão, Educação e Tecnologia Ambiental (e-ISSN: 2236-1170)

alumínio (10 a 300mg/L); reduzia-se a velocidade de agitação para $10 \mathrm{rpm}$; iniciava-se a cronometragem. E após 1 minuto, o sistema era desligado; e aguardava-se 60 minutos até a decantação total, e as análises dos sobrenadantes eram realizadas.

Nos ensaios de oxidação, os experimentos foram realizados com um volume de $4 \mathrm{~L}$ de solução resultante da primeira etapa (preparadas especificamente para esse fim, em condições otimizadas em termos de $\mathrm{pH}$ e dosagem). As amostras foram retiradas pelo septo do tanque do reator, utilizando-se uma pipeta. Em seguida: preparava-se um volume de $4 \mathrm{~L}$ do efluente oriundo da primeira etapa; transferia-se a solução para o tanque do reator; estabelecia-se o fluxo contínuo de água de arrefecimento no reator, para o controle da temperatura estabelecida para o ensaio; ligava-se o agitador magnético; fechava-se a caixa do reator e ligava-se a lâmpada; simultaneamente: acionava-se o cronômetro e adicionava-se 0,4L de peróxido de hidrogênio e, por fim, retirava-se a primeira amostra, $100 \mathrm{~mL}$ para analise titulométrica da DQO e análise da Turbidez através do turbidímetro digital e em intervalos regulares de tempo (12 minutos) repetiase o mesmo procedimento de análise.

O monitoramento dos parâmetros pH, DQO, Cor, Turbidez, Sólidos Totais, Voláteis e Fixos foi realizado mediante protocolos preconizados por APHA (1995). O monitoramento do grau de mineralização das amostras foi monitorado pelos valores de sólidos fixos da amostra.

\section{RESULTADOS E DISCUSSÕES}

\section{Características dos Efluentes}

Para controle e padronização do sistema de avaliação dos resultados, as amostras foram caracterizadas como sendo de um único lote de geração e oriundas de um mesmo processo produtivo e submetido às analises dos parâmetros ambientais inerentes a sua composição. Para tal, na Tabela 1 são apresentados os resultados obtidos para as análises laboratoriais realizadas.

Tabela 1. Caracterização dos efluentes industriais brutos, resultados médios.

\begin{tabular}{|c|c|c|c|}
\hline Parâmetros & Lavagem 1:10 & Lavagem 1:5 & Amostra Bruta 1:5 \\
\hline $\mathrm{DQO}(\mathrm{mg} / \mathrm{L})$ & $2598,4 \pm 40$ & $2982,4 \pm 51$ & $4006,4 \pm 88$ \\
\hline $\mathrm{pH}$ & $9,28 \pm 0.2$ & $10,46 \pm 0.2$ & $12,38 \pm 0.1$ \\
\hline Condutividade $(\mu \mathrm{S} / \mathrm{cm})$ & $2,37 \pm 0.25$ & $3,27 \pm 0.11$ & $12,93 \pm 0.12$ \\
\hline Turbidez $(\mathrm{NTU})$ & $98 \pm 2$ & $95 \pm 2$ & $417 \pm 4$ \\
\hline Sólidos Totais $(\mathrm{mg} / \mathrm{L})$ & $2549 \pm 20$ & $2889 \pm 21$ & $9022 \pm 22$ \\
\hline Sólidos Voláteis $(\mathrm{mg} / \mathrm{L})$ & $1204 \pm 22$ & $1354 \pm 25$ & $3841 \pm 31$ \\
\hline Sólidos Fixos $(\mathrm{mg} / \mathrm{L})$ & $382 \pm 25$ & $520 \pm 31$ & $1578 \pm 42$ \\
\hline
\end{tabular}

\section{Coagulação-floculação}

Através dos Testes de Jarro foi possível avaliar o efeito do $\mathrm{pH}$ do meio no tocante à redução da DQO e a remoção da turbidez. Os resultados apontam para um pH ideal como sendo o 
valor igual a 3,00, o que mostra que o meio ácido favorece o processo. Estes resultados são correspondentes a uma padronização da concentração aplicada de sulfato de alumínio $\left(\mathrm{Al}_{2} \mathrm{SO}_{4}\right)$ em cerca de $200 \mathrm{mg} / \mathrm{L}$ para a amostra do efluente bruto. Dessa forma, obteve-se uma remoção de DQO de cerca de $19 \%$ e da turbidez em patamares de $90 \%$, isto para um tempo de decantação de cerca de 60 minutos. Na Figura 3 são apresentados os resultados obtidos com toda a campanha de experimentos realizados.

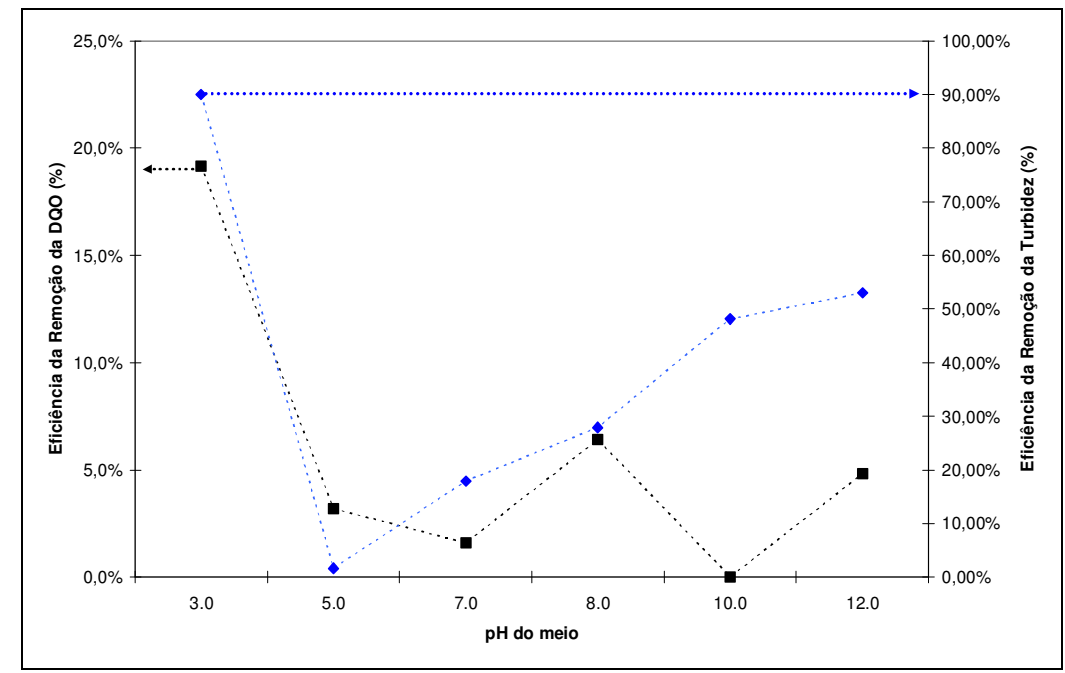

Figura 3. Efeito do pH do meio no processo de floculação frente a remoção da DQO e a turbidez dos efluentes do processo de alvejamento (lavagem e oxidação).

Pela Figura 3 observa-se ainda, que a turbidez passa por um ponto de mínima remoção, o que é comumente evidenciado na fase de neutralização, onde não se atinge os patamares de desestabilização do meio, de forma suficiente, a favorecer a coagulação das colóides. Entretanto, quando a fase de neutralização (ou seja, consumo dos íons $\mathrm{H}^{+}$para conjugação com fontes básicas) é suspensa, e existe um excesso de íons $\mathrm{H}^{+}$, ocorre, então, as reações de coagulação e o processo de tratamento são favorecidos. No pH inicial, próprio do efluente, ocorre reações de coagulação, pois o meio já encontra-se em níveis de estabilidade propensos a tal fenômeno. Entretanto, a fase básica apresenta índices de eficiência bem inferiores a fase ácida, isso devido ao tipo de agente coagulante utilizado, o uso de outros elementos pode eliminar a necessidade da fase de neutralização, entretanto, neste trabalho mantivemos o interesse nas soluções de sulfato de alumínio, por ser um produto de fácil acesso e de custo reduzido (custo estimado de $\mathrm{R} \$ 0,15 / \mathrm{m}^{3}$ ).

Na Figura 4, são apresentados os resultados dos ensaios realizados com o pH fixado em 3,0, onde se investigou a faixa de adição do agente coagulante em níveis de 10 a $300 \mathrm{mg} / \mathrm{L}$. Os resultados obtidos são expressos em relação à remoção da DQO, tendo-se obtido um pico máximo de eficiência em 30\% para uma dosagem de $100 \mathrm{mg} / \mathrm{L}$. 
Rev. Elet. em Gestão, Educação e Tecnologia Ambiental (e-ISSN: 2236-1170)

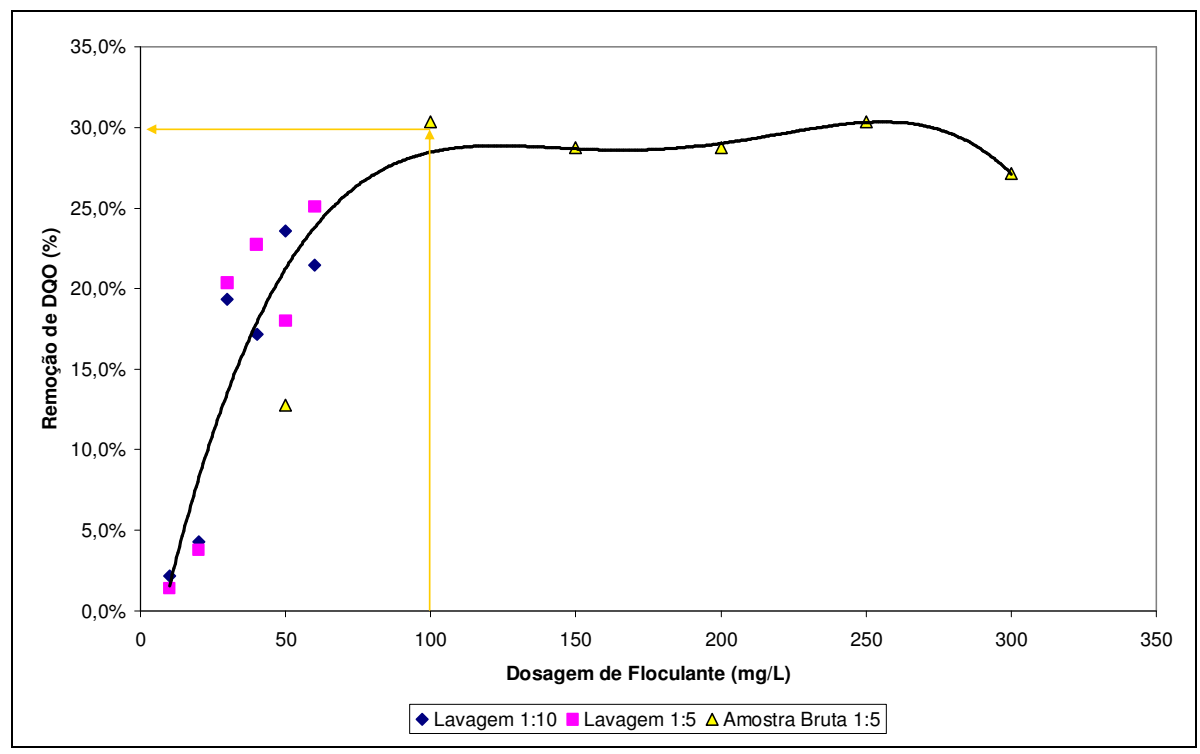

Figura 4: Efeito da dosagem de floculante (sulfato de alumínio), num pH ótimo de 3,0, na remoção da DQO mediante o processo de floculação dos efluentes do processo de alvejamento (lavagem e oxidação).

Em suma, o pré-tratamento com a técnica de floculação, seguida da decantação, atende uma eficiência global de remoção (frente ao efluente bruto) em torno de $43 \%$ de remoção de DQO e $92 \%$ da redução na turbidez dos efluentes. Contudo, a aplicabilidade e a viabilidade de inclusão deste processo em sistemas de tratamento para este tipo de efluente é recomendada, como um pré-tratamento a outras técnicas secundárias de degradação dos poluentes deste efluente (em especial, processos biológicos de tratamento).

\section{Ensaios UV-peróxido}

Visto a necessidade de complementar o tratamento, devido aos baixos níveis de remoção do pré-tratamento (apesar de bastante satisfatórios), para adequar aos padrões de lançamento em corpos hídricos ou a padrões que favoreçam o reuso desses recursos em outras atividades, foram realizados ensaios com amostras do efluente pré-tratado, ou seja, já submetido a ensaios de Jar-Test, com os parâmetros otimizados, ou seja, pH igual a 3,0 e dosagem de floculante de 100 $\mathrm{mg} / \mathrm{L}$. O preparo das amostras pré-tratadas seguiu da mesma metodologia dos testes iniciais de floculação, sendo utilizados os sobrenadantes obtidos após 60 minutos de decantação.

Na Figura 5 apresenta-se os resultados obtidos em relação a evolução da remoção de DQO nas soluções dos efluentes têxteis, em questão, durante o tratamento fotoquímico. Percebe-se que houve um decaimento linear da DQO, não ocorrendo variações significativas em relação a natureza da amostra (qual o tipo do efluente), estando esse efeito anulado. A cinética de degradação foi evidenciada como sendo de ordem zero, tendo-se um ajuste linear para o decaimento cinético observado. A regressão dos dados experimentais remete a um coeficiente de correlação, $R^{2}=0,9593$ e o coeficiente angular representa a velocidade específica da reação (k). Neste caso, o perfil da remoção dos compostos orgânicos do efluente pode ser aproximado por uma reta. Não observou-se a tendência descrita por Palm et al (2003). 
Rev. Elet. em Gestão, Educação e Tecnologia Ambiental (e-ISSN: 2236-1170)

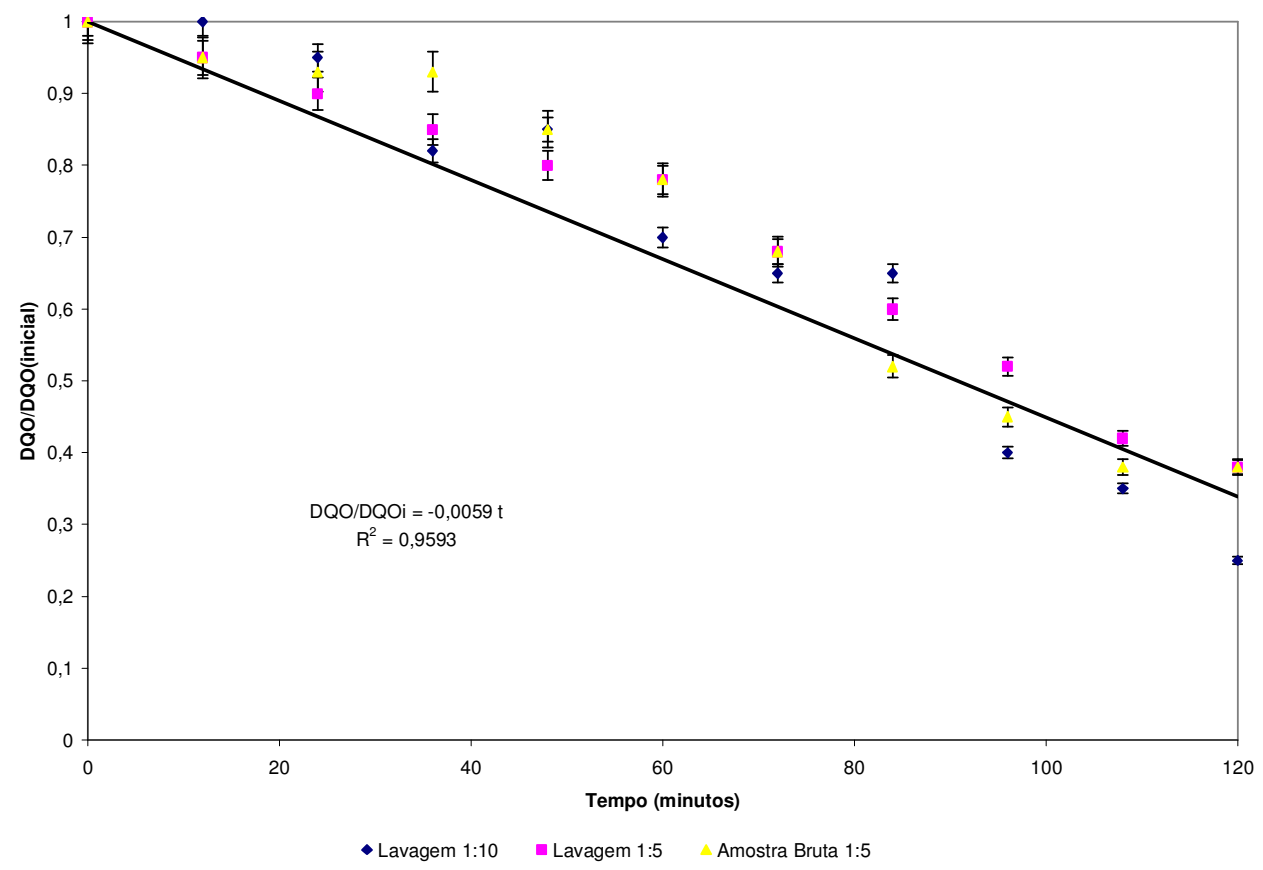

Figura 5. Remoção da DQO, no processo de UV-Peróxido, dos efluentes pré-tratados pela floculação em um pH ótimo de 3,0 e uma dosagem de floculante de $100 \mathrm{mg} / \mathrm{L}$ de Sulfato de Alumínio.

O processo de oxidação via a utilização da técnica fotoquímica, apresentou índices de remoção da DQO da ordem de $80 \%$, correspondendo a uma eficiência global do processo global das técnicas combinadas em torno de $92 \%$. Os resultados obtidos são satisfatórios e atendem aos padrões de lançamento exigidos pela resolução do CONAMA de número 430 de 2011 (eficiência de remoção superior a 80\%), apesar da DQO remanescente ser ainda significativa, em valores absolutos. Porém, inertizada, e provavelmente (especulativo) pouco reativa, já que foi resistente inclusive a ação de radicais de alto poder oxidativo, no caso o radical hidroxila.

Considerando a simplificação do modelo para projetos futuros de estações de tratamento, não foi desenvolvido o modelo matemático com múltiplas etapas para representar os dados experimentais.

Em relação a remoção da turbidez, tem-se representado na Figura 6 a cinética de decaimento. Observa-se que a remoção é bastante significativa. Atingindo-se valores inferiores a 8 NTU, chegando-se a 2 NTU, num período de tempo de 120 minutos. Para o caso da turbidez, a influência da origem da natureza da amostra é significativa, tendo-se uma maior dificuldade de remoção em função dos valores iniciais. Ou seja, a amostra bruta numa proporção de 1:5, com valores mais elevados de turbidez tende a ter valores residuais mais elevados, entretanto, com a normalização dos valores, em função da leitura inicial, eliminam tal efeito, dando um patamar de eficiência equivalente para os três sistemas. Porém, como as normas, em termos de padrões de lançamentos, são preconizadas enquanto valores individuais, assim são apresentados tais resultados. Ao contrário da DQO, que o índice de remanescente é o requerido. Além disso, o 
efluente de lavagem na proporção de 1:10, apresentou uma melhor eficiência de remoção desse parâmetro, por ser mais diluído, e com isso possuir uma menor DQO e uma menor incidência de partículas coloidais, o que facilita a mineralização e aumenta a eficácia do processo global. Observa-se nessa variável uma clara tendência de duas etapas de degradação, removendo inicialmente os componentes que interferem em menor grau nos níveis de cor e turbidez, e conseqüentemente na etapa seguinte com a remoção dos compostos que alteram mais tais variáveis.

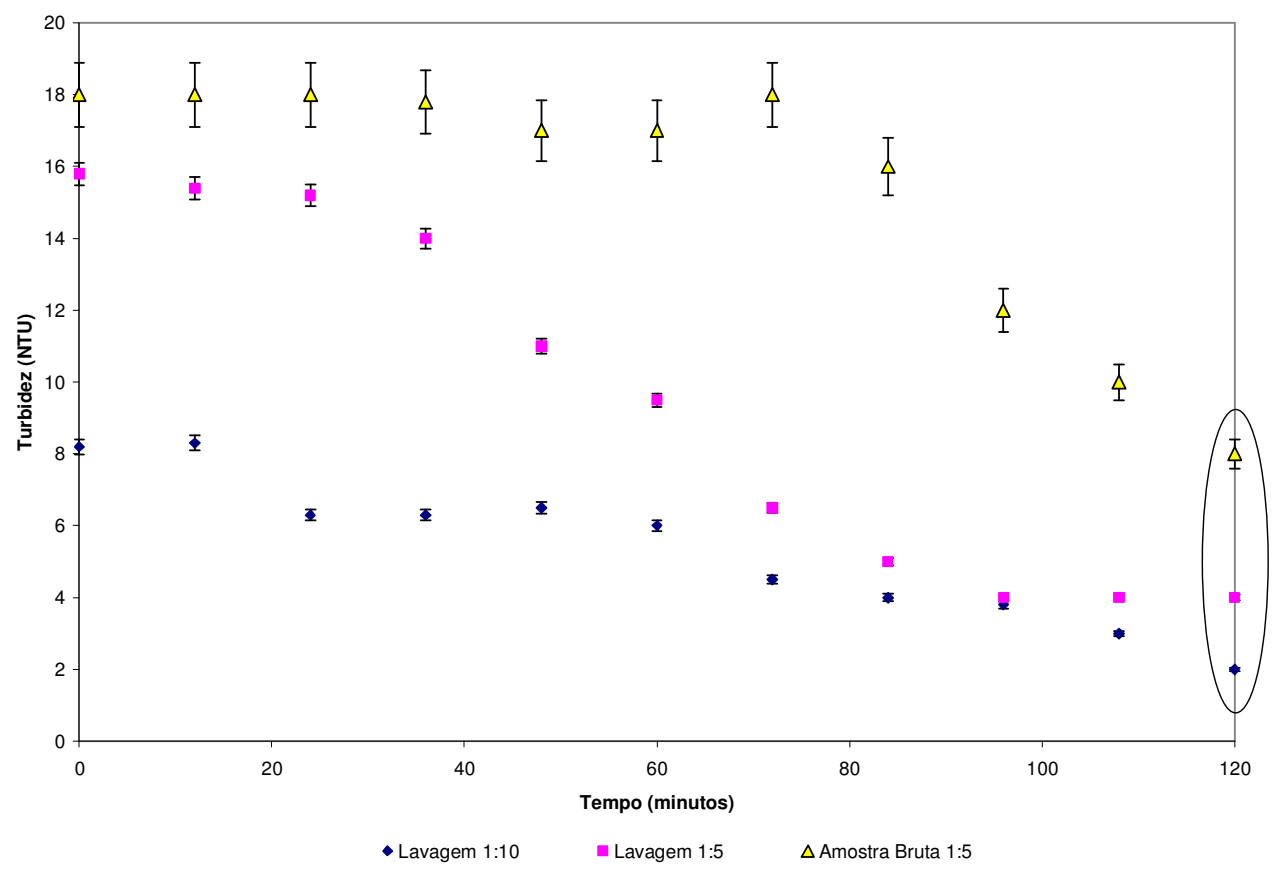

Figura 6. Remoção da Turbidez, no processo de UV-Peróxido, dos efluentes pré-tratados pela floculação em um pH ótimo de 3,0 e uma dosagem de floculante de $100 \mathrm{mg} / \mathrm{L}$ de Sulfato de Alumínio.

Na Figura 7 é apresentado registro fotográfico, antes e após o processo, que evidenciam a intervenção das técnicas e sua atividade na remoção da turbidez dos efluentes. 


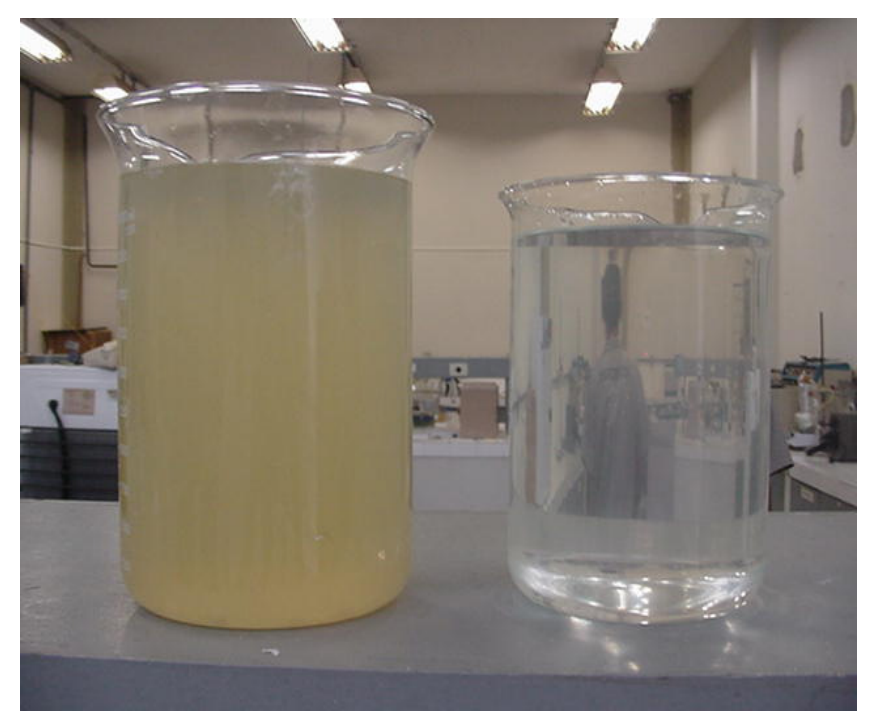

Figura 7. Fotografias registradas durante o processo de oxidação por meio da técnica fotoquímica de UV-Peróxido. Efluente bruto (esquerda) x Efluente tratado (direita).

Por fim, na Figura 8 são apresentados os resultados globais obtidos com o tratamento combinado em relação a degradação da matéria orgânica quimicamente degradável.

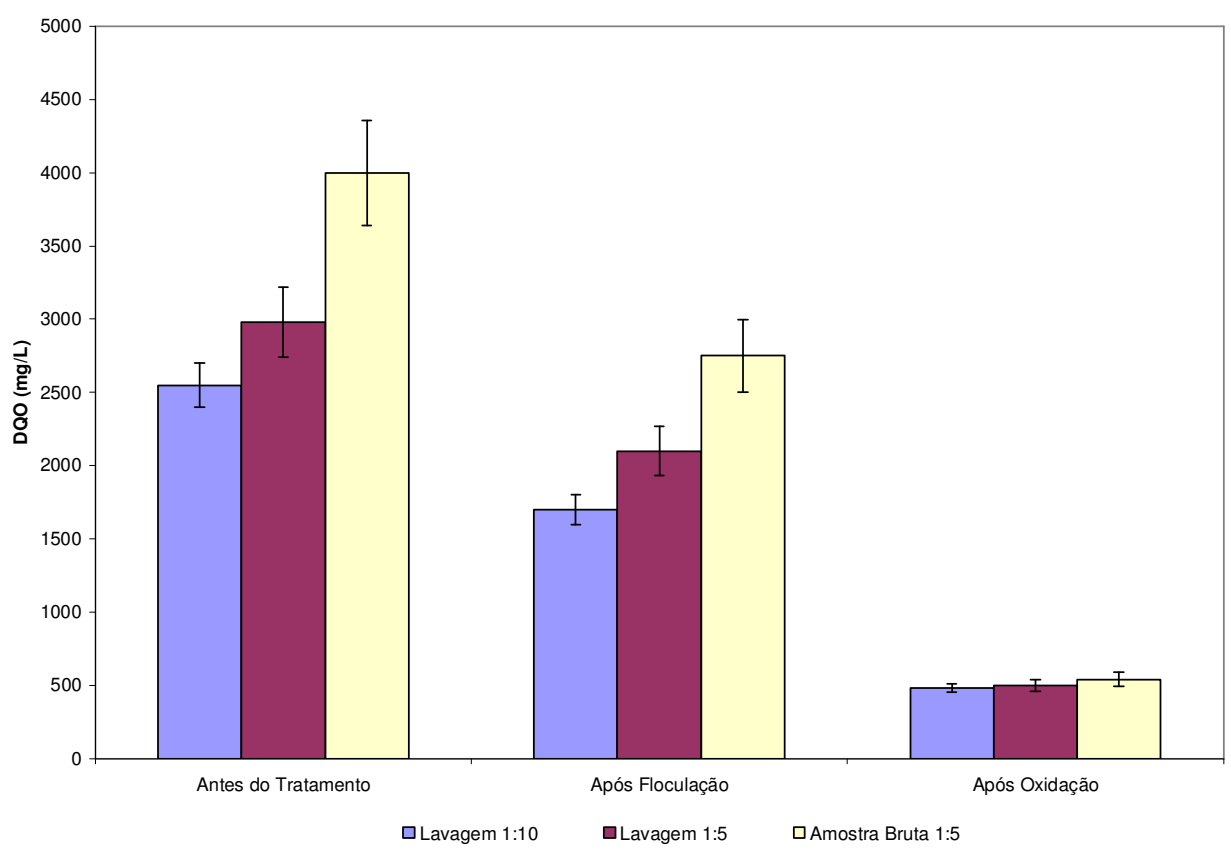

Figura 8. Remoção da DQO, nos diversos processos de tratamento submetidos.

A mineralização da matéria orgânica pode ser observado pelo aumento no percentual de sólidos fixos frente ao teor de sólidos totais presentes na amostra, conforme observado na Figura 9. 
Rev. Elet. em Gestão, Educação e Tecnologia Ambiental (e-ISSN: 2236-1170)

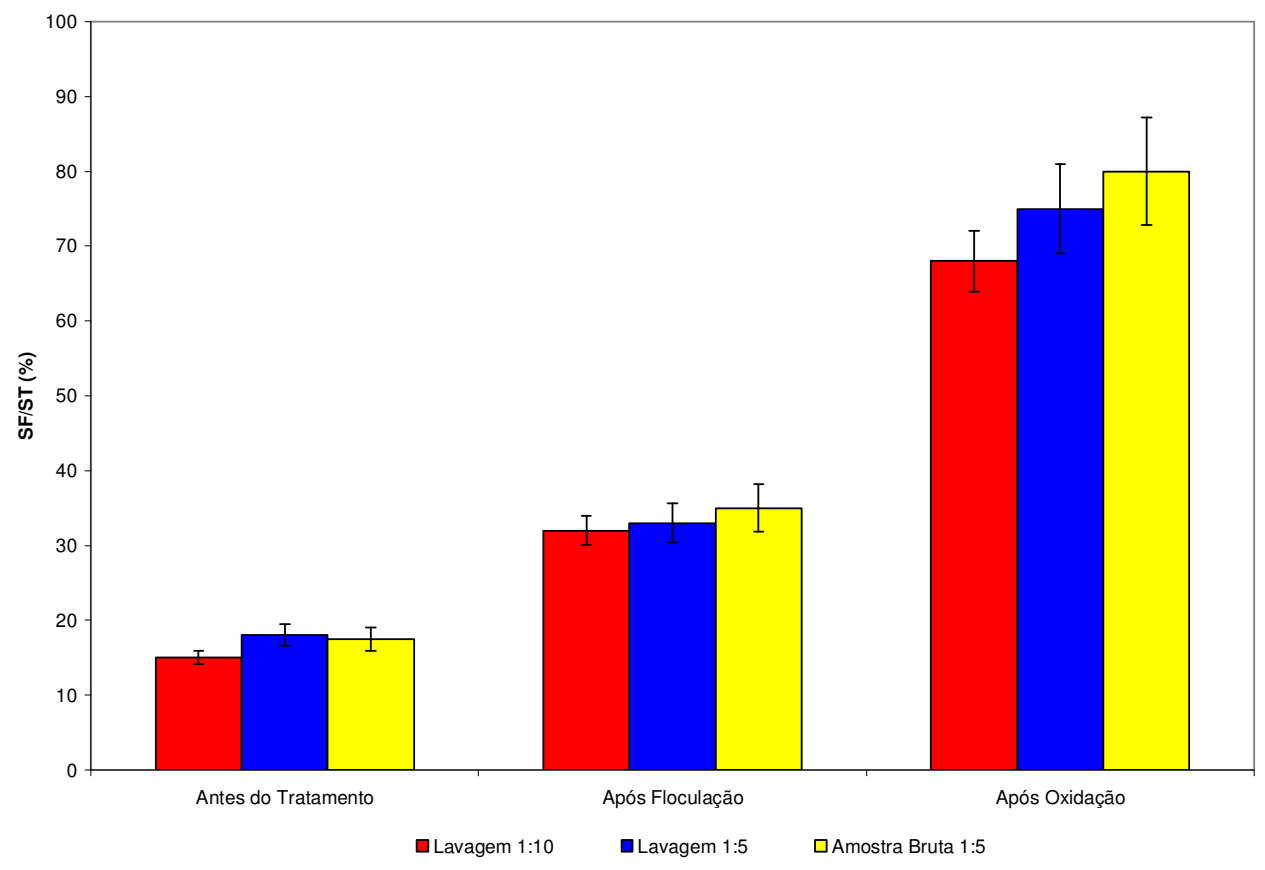

Figura 9. Aumento da relação de sólidos fixos (SF) frente ao teor de sólidos totais (ST) presentes nas amostras.

\section{CONCLUSÃO}

De acordo com os resultados obtidos, pode-se concluir que:

1. O processo de pré-tratamento do efluente através da técnica físico-química coagulação/floculação mostrou-se satisfatório na remoção dos sólidos suspensos presentes nas amostras dos efluentes, contribuindo assim para uma redução nos índices de DQO da ordem de $30 \%$ e da turbidez em $90 \%$.

2. Os ensaios, com a técnica de oxidação $U V / \mathrm{H}_{2} \mathrm{O}_{2}$, mostraram-se bastante eficazes na mineralização da matéria orgânica presente no efluente, contribuindo para redução de DQO da ordem de $80 \%$ e redução da turbidez para valores da ordem de 1,8 NTU.

3. A combinação das duas técnicas revelou uma excelente eficiência no que diz respeito ao processo de degradação, dentro da faixa de valores dos parâmetros estudados.

4. A inclusão de um tratamento biológico após esse sistema se torna uma boa alternativa na eliminação plena dos constituintes orgânicos residuais do efluente, desde que o peróxido residual seja removido. 


\section{REFERÊNCIAS BIBLIOGRÁFICAS}

AGLADZE, G. R., TSURTSUMIA G. S., JUNG, B.I., KIM J., S., GORELISHVILI, G. Comparative study of chemical and electrochemical Fenton treatment of organic pollutants in wastewater. Journal Applied Electrochemical, n. 37, p. 985-990, 2007.

APHA - American Public Health Association. American Water Works Association. Water Environment Federation. Standard Methods for the examination of water and wastewater.19. (1995).

ARAÚJO, F. V.; YOKOYAMA, L; Remoção de cor em soluções de corantes reativos por oxidação com H2O2/UV, Química Nova, Vol. 29, № 1,11-14, 2006.

BAUTISTA, P., MOHEDANO, A. F., CASAS, J. A., ZAZO, J. A., RODRIGUEZ, J. J. An overview of the application of Fenton oxidation to industrial wastewaters treatment. Journal of Chemical Technology and Biotechnology, n. 83, 1323-1338, 2008.

BRIÃO, V. B., TAVARES, C. R. G. Ultrafiltração como processo de tratamento para o reuso de efluentes de laticínios. Engenharia Sanitária e Ambiental, n. 12, p. 134-138, 2007.

CISNEROS, R. L.; ESPINOZA, A. G.; LITTER, M.I.; Chemosphere, 48, 393, 2002.

CONAMA. CONSELHO NACIONAL DE MEIO AMBIENTE. Resolução no 430 de 13 de maio de 2011. Dispõe sobre as condições e padrões de lançamento de efluentes, complementa e altera a Resolução no 357, de 17 de março de 2005, do Conselho Nacional do Meio Ambiente CONAMA.

GEORGIOU, D.; MEDELIS, P.; AIVASIDIS, A.; GIMOUHOPOULOS, K.; Dyes pigm., 52, 69, 2002.

HALLOWELL, C. 1996. Farmers of the sea. Time Magazine. October, 28, p.52-53.

HUTCHINGS, P. A. SAENGER, P. 1987. Ecology of mangroves. University of Queensland Press. Brisbane. 388pp.

IDEMA. Disponível em: http://www.idema.rn.gov.br. Acesso em: 11/06/2012.

JERONIMO, C. E. M. et al. Estudo comparativo entre técnicas de determinação da matéria orgânica em efluentes industriais de composição carbonácea. HOLOS, Ano 28, Vol 2. 2012.

KEMPKA, A. PAGLIARINI, C. G.,; ROBAZZA, W. Estudo das concentrações de ferro e peróxido de hidrogênio na oxidação química de efluente proveniente de laticínio. Engenharia Ambiental: Pesquisa e Tecnologia, Brasília, DF, 9.1, 1206 2012. Disponível em: <http://189.20.243.4/ojs/engenhariaambiental/viewarticle.php?id=682>. Acesso em: 0607 2012. 
LACERDA, L. D. et al. Contaminação dos metais pesados nas bacias inferiores dos rios Curimatau e Açu (RN) e rio Jaguaribe (CE) In: Impacto do ambiente Exógeno sobre a Carcinicultura Marinha. Associação Brasileira dos Criadores de Camarão ( $A B C C)$, Instituto de Ciências do Mar (LABOMAR-UFC), Sociedade Internacional para Ecossistemas de Manguezal (ISME-BR). Fortaleza, 87 p., 2004.

PALM, W. U. et al. Journal of Photochemistry and Photobiology A: Chemistry 156 (2003) 105-114.

POON, C. S.; HUANG, Q.; FUNG, P. C; Chemosphere, 38, 1005,1999.

SWAMINATHAN, K.; SANDHYA, S.; CARMALIN-SOPHIA, A.; PACHHADE, K.; SUBRAHMANYAM, Y.V.; Chemosphere, 50,619, 2003. 